ЧЕРНЫШОВ Алексей Геннадиевич - доктор политических наук, профессор кафедры государственного и муниципального управления Финансового университета при Правительстве РФ (125993, Россия, г. Москва, Ленинградский пр-кт, 49; ag555@таil.ru)

\title{
СТРАТЕГИЯ И ФИЛОСОФИЯ ЦИФРОВИЗАЦИИ
}

Аннотация. Сегодня многие проблемы цифровизации, как кажется поначалу, связаны исключительно с вопросами применения различных информационных и компьютерных технологий, математических и иных моделей. На самом деле цифровизация - это проблема прежде всего социально-политическая и социогуманитарная. А если так, то без осмысления методологических и стратегических задач нынешней и будущей цифровизации применительно к развитию и нахождению в цифровом мире самого человека нам никак не обойтись.

Ключевые слова: человек в цифровом мире, социогуманитарный фактор развития, технизация общества, цифровая экономика, философия цифровизации.

B России и в других странах присутствует новый мем 1 - так называемая цифра, цифровая экономика, цифровое общество. В кипении мыслей и страстей на этой почве немало того, что в информатике принято называть шумом. В России немало людей - политиков, высокопоставленных чиновников, глав крупнейших банков, государственных и частных компаний, - связывающих успешное развитие страны именно с идеологией и практикой «цифры» - от искусственного интеллекта до криптовалюты. Такое впечатление, что здесь, наряду с подлинными достижениями, немало и иллюзий, и прямых заблуждений.

Поэтому столь важно провести тщательную работу по определению того, что может дать стране вступление на путь ее «цифровизации». При этом следует иметь в виду, что цифровые инновации пока незначительно трансформируют мир по сравнению с изобретениями предыдущих промышленных революций. Это во многом связано с поведением самих людей, деловых кругов, которые пока не видят большой отдачи от использования новейших цифровых технологий.

И вот почему. По сути, «цифра» - это технологии обработки так называемых больших данных (Big date). Но, как показывает практика, их обработка далеко не всегда оказывается эффективной с точки зрения достижения поставленных производственных, социальных, управленческих целей. В принятии решений определяющую роль по-прежнему играет человек - его интеллект, опыт, интуиция. В то же время в связи с определенной исчерпанностью технократической модели развития мира Россия вполне бы могла разработать и предложить сообществу проект социогуманитарного содержания [Лепский 2012] как важнейшую составляющую формирующегося нового мирового устройства.

Для формирования базового тезиса в наших размышлениях прежде всего заметим, что сами по себе технологии, которые вошли и входят в повседневную жизнь граждан, несут в себе новые возможности для коммуникации, потенциально настроены на выявление нового знания и овладения им, повышают эффективность развития бизнеса, позволяют с большей основательностью формировать алгоритмы для выработки прогнозов и стратегий на будущее.

Однако погоня за «цифрой» и бездумным рукотворным ускорением технического прогресса ради получения все большей прибыли, задействования манипулятивных форматов практик ставит на повестку дня кардинальные вопросы,

\footnotetext{
1 Мем - это нечто или некто, ставшее популярным во всемирной паутине, ставшее предметом массового хайпа и выраженное в виде картинки или фотографии с подписью.
} 
связанные с определением смыслового наполнения подобных трансформаций и влиянием на психическое и физическое здоровье человека.

Одно дело, когда мы рассматриваем пользу от введения инноваций и понимаем, как расширяется при этом мир отдельного индивидуума. Другое дело, когда этот мир, как шагреневая кожа, сужает горизонт разумного существа до виртуального ящика. И как бы много ни было в нем информации и красивых видео, выйти из сети и оторваться от его чар человеку становится все труднее.

Таким образом, мы вполне определенно должны понять границы и потребности самого человека в использовании цифровых решений.

Мы можем попытаться выстроить парадигму движения в общество знаний, в котором ценностные и информационные большие данные будут играть все возрастающую роль и приносить гражданам новые возможности для осмысления действительности, принятия решений о выстраивании личностной модели жизни. Мы же можем собственными руками способствовать формированию и совершенно иного мира - это когда будем захлебываться в цифровизованных муляжах ${ }^{1}$ и тонуть в растущем в геометрической прогрессии информационном мусоре и при этом в модном пустословии, в т.ч. и в дискуссиях о необходимости повышения производительности труда, постепенно усиливать равнодушие к живым людям.

Второй вариант практик сегодня семимильными шагами набирает обороты. А все потому, что большая часть политического и бизнес-истеблишмента рассматривают «цифру» в качестве ключа, открывающего все замки у дверей, за которыми, по их мнению, наступит эра всеобщего благоденствия.

При этом сама система политики и управления формирует информационные фантомы. Порой чиновники своими формальными показателями и созданием всевозможных ГАСов и ГИСов 2 с их неполнотой информации и приукрашиванием собственными руками создают цифровую дополненную реальность, но только чиновничьего типа, и за большие деньги. И мотивация тут иная.

Многим людям такой виртуальный и формальный мир неинтересен. Они стараются убежать туда, где хотя бы что-то осталось натуральным и естественным. Но оставить в покое граждан глобальные «реформаторы» не могут. Навязываемые услуги под «крышей» государственной машины действуют безотказно, и людей всяческими способами хотят насильно сделать «счастливыми». Поэтому даже в самом сетевом пространстве формируется подпольный интернет [Бартлетт 2017]. И это далеко не только темная криминальная сторона информационного мира. Часть людей хочет спрятаться там от тотального и общедоступного Интернета, создавая, как и в реальной жизни, для себя и своего маленького сообщества небольшие цифровые лагуны.

Правительственная программа «Цифровая экономика» появилась летом 2017 г. ${ }^{3}$ Раз мы говорим о трендах на большую цифровизацию и использование Big data в системе принятия решений, то вполне резонно было бы ожидать формирования целенаправленной политики в цифровой сфере, причем понятной не только управленцам, но и рядовым гражданам. По мнению экспертов, принятая программа - это в большей степени риторический документ, ставший

\footnotetext{
1 Привалов А. О каких-то жалких восьми триллионах. - Эксперт. 2018. № 15(1071). 9 апр. Доступ: http://expert.ru/expert/2018/15/o-kakih-to-zhalkih-vosmi-trillionah/

2 ГИС - государственный информационная система, ГАС - государственная автоматизированная система.

3 Распоряжение Правительства РФ от 28.07.2017 года № 1632-р об утверждении программы «Цифровая экономика Российской Федерации».
} 
частью маркетингового хайпа ${ }^{1}$, возникшего в последние годы вокруг цифровой трансформации ${ }^{2}$. Таким образом, развитие определенных технологических решений в ИТ-индустрии и сопутствующие этим информационным потокам изменения в сфере роботизации и появления элементов искусственного интеллекта вызвали ажиотажный спрос на инновации. Но еще больше - запрос на осмысление данной ситуации с точки зрения фактически революционного изменения самого человеческого социума.

Естественно, для того чтобы выстраивать новую траекторию движения, необходимо сформировать стратегию развития, в т.ч. и на долгосрочную перспективу, которая будет понятна и принята большинством. Главное, сегодня важно понимание того, что мы с открытыми глазами и явным осмысленным пониманием ситуации движемся к определенным рубежам.

Если же считать, что реформа может быть успешной только тогда, когда ее осмысленно поддерживают большинство граждан, то формирование стратегии развития должно иметь четкие и понятные приоритеты.

В 2014 г. был принят Закон о стратегическом планировании ${ }^{3}$. Но сама система стратегического планирования в стране за эти годы так и не появилась. Закон плотно увяз в бюрократической паутине и сегодня безнадежно устарел, так и не продвинув процесс вперед.

Хаотическое и ситуативное управление не позволяет на государственном уровне вырабатывать и согласовывать с самим обществом основные шаги по реализации и естественному вписыванию в социум новых практик. Получается, что вертикаль власти работает сама на себя, на свой «личный» интерес. А ведь в оптимальном формате государство должно воспринимать и адаптировать под современные вызовы импульсы, идущие «снизу». Как резонно замечает Г. Клейнер, ${ }^{4}$ разработка стратегии развития как государства, так и отдельно взятого региона должна начинаться «снизу» - т.е. с предприятий, имеющих свое видение относительно происходящих в экономике процессов. При этом стратегия каждого экономического субъекта (предприятия, региона, отрасли) должна стать частью сетевой структуры стратегий в масштабе России. Цифровая экономика - это, прежде всего, все-таки экономика, а не «цифра». А сама экономика, если брать родовое понятие, - это искусство управления домашним хозяйством, там, где действует, творит и работает сам человек. Сумма личных мотиваций к работе, стремление к творчеству и самосовершенствованию - вот истинный двигатель хозяйственного роста. Изолированные от самого человека, вырванные из контекста стратегии имеют мало шансов на выживание и успешную реализацию ${ }^{5}$. И это особенно важно с учетом расширения практик, связанных с интеграцией в общее глобальное пространство, в котором мы сегодня существуем. И тут кооперация, возможности солидарного развития не менее, а может быть, и более важны, чем возведенная в абсолют теория конкуренции.

Мы видим, что условиях бурного развития цифровых технологий выявились

1 Хайп (англ. hype) - навязчивая реклама; шумиха, ажиотаж. Существует созвучный глагол, который означает «раскрутить; раздуть».

2 Яппаров Т. Цифровизация без хайпа. Программе развития цифровой экономики не хватает внятных приоритетов. - Ведомости. 2018. 4 апр. Доступ: https://www.vedomosti.ru/opinion/ articles/2018/04/04/755769-tsifrovizatsiya-haipa?utm_campaign=newspaper_04_04_2018\&utm_ medium $=$ email\&utm source $=$ vedomosti

3 Федеральный закон от 28 июня 2014 г. № 172-Ф3 «О стратегическом планировании в Российской Федерации». Доступ: http://base.garant.ru/70684666/

4 Клейнер Г. - член-корреспондент РАН, доктор экономических наук, заместитель директора ЦЭМИ РАН.

5 Ракуль Е. Каждая стратегия как душа - она индивидуальна. - Эксnерт. 2018. № 10(1066). 5 марта. Доступ: http://expert.ru/south/2018/01/kazhdaya-strategiya-kak-dusha---ona-individualna/ 
некоторые фундаментальные проблемы - к примеру, вопрос о свободе личности как таковой, и в сети - в частности. С одной стороны, расширение интернет-пространства дало конкретному человеку, по сути дела, неограниченные возможности использования той или иной информации. Социальные практики в сети стали играть серьезную роль в формировании элементов электронной демократии и т.д. Вместе с тем обратная сторона медали - проблемы безопасности нахождения в сетевом мире, «обнажение» самого человека за счет использования в сети и электронных устройствах его личных данных, незащищенность от манипуляции сознанием, киберпреступности, слежки со стороны спецслужб [Кин 2016].

Цифровой мир способствовал тому, что вся жизнь людей оказалась как на ладони. Возникло целое новое направление «финтех». Это лишь отчасти специализация на использовании технологии и инновации, чтобы конкурировать с традиционными финансовыми организациями в лице банков и посредников на рынке финансовых услуг. На самом деле «финтех - история про поток данных о нашей жизни и про то, кто получит больше информации об этом потоке» 1 . Как итог - возможная потеря индивидуумом свободы как таковой, а не ее обретение и укрепление.

При этом, как это ни парадоксально прозвучит, цифровая революция делает нас все более зависимыми от технологий и в чем-то более одинаковыми. Общество становится «пластиковым»: мы «все больше похожи друг на друга, в нас все меньше креативности, индивидуальности, независимости» ${ }^{2}$. Особенно примечательно, что эти мысли высказал Стив Возняк ${ }^{3}$ - один из пионеров компьютерной индустрии.

Право людей на неприкосновенность частной жизни начинает «трещать по швам». Никто не имеет права, например, прослушивать телефонные разговоры и наблюдать за тем, что они делают у себя дома, без санкции суда. Однако современные технические возможности позволяют легко нарушать то, что гарантирует буква закона. Более того, вполне законным способом граждан пытаются принудить всецело раствориться в информационном мире, насильно и побыстрее затолкать в «цифру» - отобрать бумажные книги и учебники, внедрить повсеместно банковские карты и электронные деньги и тем самым фактически получить возможность установить невиданные ранее способы контроля над личностью. Уже сегодня блокчейн позволяет совершенно иначе, чем раньше, отслеживать все действия пользователей внутри системы. Таким образом, вполне обоснованны опасения, что «Большой брат», используя «большие данные», будет знать о каждом из нас буквально все. При этом формируется «параллельное» законодательство, которое позволяет делать анонимной информацию о конкретных персонажах из правящего бомонда, дабы не раздражать всю остальную публику какими-то шокирующими сведениями из биографии или об уровне богатства последних.

В этом же ряду фактически краеугольная для западной цивилизации тема проблема частной собственности. Каким образом удержать частнособственнические основания развития мира, если «цифра» фактически отбирает последние

\footnotetext{
1 Маврина Л. Опасный новый криптомир. - Эксперт. 2018. № 15. 9-15 апр. С. 44. Доступ: http:// expert.ru/expert/2018/15/chem-myi-zaplatim-za-finteh/; http://expert.ru/expert/2018/15/opasnyij-novyijkriptomir/

2 Носырев И. Цифровая революция делает нас все более одинаковыми. - РБК. 2018. 6 апр. Доступ: https://www.rbc.ru/own_business/05/04/2018/5ac5fd839a79479763f1b3be

3 Стив Возняк - американский изобретатель, инженер-электронщик и программист, соучредитель (в 1976 г.) компании Apple Computer (ныне Apple Inc.) вместе со Стивом Джобсом и Рональдом Уэйном. В середине 1970-х гг. в одиночку спроектировал компьютеры Apple I и Apple II, которые начали «микрокомпьютерную революцию» и определили развитие отрасли.
} 
личные приобретения граждан - бумажные деньги (не за горами введение электронных денег и вообще перевод всего процесса в криптовалюты), авторские права (сеть быстрее формирует новые идеи, чем их можно успеть зарегистрировать и юридически оформить), критическое мышление и понятийный аппарат.

Во весь рост встает проблема защиты биометрических данных, которая будет самым главным при развертывании системы удаленной идентификации. Пока с высоких трибун заявляется право граждан на отказ от сдачи в систему «слепка» своего голоса и лица ${ }^{1}$. Но это сегодня, а завтра? Под предлогом защиты информации от внешних воздействий гражданам пытаются внушить мысль о благоприятности тотальных ограничений сети при одновременном сканировании отдельного человека. Если ты отказываешься следовать распространяемым правилам, то можешь и не заметить, как станешь изгоем в цифровом обществе. Это плата за свободу, если гражданин не захочет подключиться ко всем коммуникациям и сдать все данные о себе практически добровольно. Хотя даже в таких тотальных условиях действия цифры все большее число граждан начинают задумываться о том, каким образом отказаться от рабского нахождения в сети ${ }^{2}$.

Сканирование сетчатки глаза, отпечатков пальцев - раньше такое применялось только по отношению к преступникам. То есть, была некоторая часть асоциальных элементов, от которых таким способом пытались защитить все остальное добропорядочное и законопослушное общество, и действовал изначально родовой принцип презумпции невиновности. А сейчас все меняется кардинально и ставится с ног на голову. К чему это может привести? К полному переформатированию всей нашей социальной жизни, нашего привычного социума. Просчитали ли мы последствия таких шагов? И вообще, какой мир в будущем мы хотим построить? Может быть, отсутствие у нынешней правящей элиты образа будущего и говорит о том, что его и не хотят искать и строить как раньше, пытаясь найти взаимоприемлемые решения для большинства? Вероятно, мы недалеки от истины, и можно говорить о том, что правящее меньшинство видит в будущем формате практик только себя и роботов. То есть, изначально весь так называемый цифровой мир создается не для того, чтобы с помощью новейших технологий получить новый структурированный массив знаний и сохранить смыслы, а для того, чтобы освободить себя от общения с «неблагодарным» и непредсказуемым «быдлом» и общаться только с послушной «машиной», а через нее - с небольшим контингентом обслуживающего живого персонала.

Тем самым, в базовых конструкциях человеческого мироустройства начинает испытываться на прочность принцип естественного права, которое излагает законы, выводимые из самой «природы разума человеческого» [Куницын 2011]. Как подчеркивал в свое время выдающийся русский юрист А.П. Куницын ${ }^{3}$, именно власть должна быть строго ограничена в своих проявлениях, и все ее действия должны быть направлены на охрану прав и интересов населения, общества и детей. И только в этом случае она может быть признана властью законной и справедливой.

В современной ситуации основные ограничения накладываются на самих граждан. Уже сегодня в развитых странах цифровизация и роботизация достигли

\footnotetext{
1 Долженков А. В банк по отпечатку. - Эксперт. № 15(1071). 2018. 9 апр. Доступ: http://expert.ru/ expert/2018/15/v-bank-po-otpechatku/

2 «Жизнь проходит мимо». Почему россияне бегут из соцсетей. 13.04.2018. Доступ: https://ria.ru/ society/20180413/1518505323.html?referrer_block=index_daynews3_1

3 Куницын Александр Петрович (1783-1840), юрист. Преподавал в Царскосельском лицее, оказал большое влияние на А.С. Пушкина. Основной труд - «Право естественное» (ч. 1-2, 1818-1820).
} 
значительных высот. Только оказывается, что запущенный «бумеранг» сильно ударяет по правам рядового обывателя. В той же самой Европе цифровизация и роботизация бьет «по живому» - оказывает самое непосредственное воздействие на вымывание среднего класса. А это ведь это становой хребет всей европейской демократической системы. Выходит, что власть, инициируя бурный рост технологических изменений, не особо-то и задумывается о том, кто и что завтра будет составлять основу мировоззренческой, социокультурной и экономической основы нации, чем будут заниматься многие сегодняшние высококвалифицированные рабочие и инженеры. Богатые будут богатеть, нижнюю часть социальной иерархии будут заполнять мигранты и разорившиеся «середнячки». А «ядро» общества будут заполнять роботы?

Средний класс в таком формате практик становится не особо нужным. А то вдруг начнет еще разбираться в качестве продукции, менять свои потребительские приоритеты. И думающий избиратель тоже не нужен. И гражданин со своими правами и ответственностью, собственно, тоже не нужен. Поэтому обыватель распыляется по миру в качестве «неграждан». Поэтому получается, что пока все тенденции говорят о том, что нас ждет общество программистов и олигархов (с небольшим количеством обслуживающего персонала и части ученых, работающих на потребности «золотого миллиарда»).

Многие мыслители прошлого, включая Карла Маркса, подчеркивали важность того, что общество в своем развитии выйдет на такие рубежи, когда время, высвобождающееся от тяжелого труда, будет потрачено на творчество. Свободное время должно стать пространством для развития личности. Богатство государства будет определяться наличием свободного времени у его граждан. Но сейчас парадигма движения другая - извести всеми силами самого человека как биологическое существо. А для рядовых граждан в качестве насущной задачи стоит не проблема развития, а вопрос выживания...

В сегодняшней модели устройства мы наблюдаем вполне заметные черты по движению человеческого сообщества к такой форме глобального тоталитаризма, которая и не снилась Ханне Арендт ${ }^{1}$ и Фридриху фон Хайеку ${ }^{2}$. И произрастает он через так называемые неолиберальные теории развития социума, в которых основой мироздания является отнюдь не человек, и даже не прибыль как экономическая категория, а откровенная внеэкономическая нажива.

Человечество как целое утрачивает смысл своего социального бытия, убивает сам «интеллектуальный фактор» понимания действительности [Зиновьев 2006] и, говоря современным сленгом, растворяется в глобальной цифровой сети.

Вот она, дилемма современного развития: или обретение общества знания и свободы духа, или общество потребления и окончательное порабощение через «цифру». Сегодня современные технологии во многом уже закабалили людей, открыв перспективу ничем не ограниченного потребления, комфорта и развлечений, с одной стороны, и тотального контроля над людьми, управления ими - с другой. Как в таких условиях осуществить возврат человека к себе самому, к очеловечиванию природы? Практически заново построить мир, в котором человек не будет чужим среди чужих, а будет чувствовать себя как свой среди своих [Фромм 1992]?

Осуществить такие преобразования можно путем формирования ценност-

1 Ханна Арендт (Hannah Arendt; 1906-1975) - немецко-американский философ еврейского происхождения, политический теоретик и историк, основоположница теории тоталитаризма. Основной труд - «Истоки тоталитаризма».

2 Фридрих Август фон Хайек (Friedrich August von Hayek; 1899-1992) - австрийский экономист и философ, представитель новой австрийской школы, сторонник либеральной экономики и свободного рынка. Одна из основных работ - «Дорога к рабству». 
ного знания, обретенного человеком за свою историю. И в этом процессе важнейшую роль могут сыграть «цифра» и искусственный интеллект, если информационные технологии будут продолжением культуры и морали, ее развитием, наполняя новым смысловым содержанием современные процессы.

В данном процессе важно поднять на поверхность глубинные пласты знаний классической литературы и фундаментальной науки, которые в том или ином виде сегодня выведены из круга информационного интереса и практически не используются для того, чтобы формировать настоящее и будущее развитие того или иного человеческого социума. Зато с чрезвычайной активностью и страстностью используются многочисленные медиа: СМИ и социальные сети 1 + сетевое покрытие деятельности организаций и предприятий в цифровом пространстве ${ }^{2}$. Это все поверхностные, сиюминутные всплески сознания, которые отражает «цифра», подчас лишь «бульканье» в сети. А глубинные знания оказываются на периферии и еще более, чем ранее, игнорируются.

При этом нельзя допустить того, чтобы человек попал в прокрустово ложе унифицированных и приукрашенных для него цифр, фактов и видеокартинок; чтобы такая социальная болезнь, как наркомания, не стала такой же тяжкой социальной дисфункцией и не привела к эпидемии в виде цифромании XXI в. Определенная унификация цифровых стандартов и информационных потоков возможна при разработке и реализации бизнес-процессов, формировании отраслевых и иных электронных архивов документов, в т.ч. для поддержания полного жизненного цикла работы того или иного предприятия. Некоторая гармонизация стандартов и общих «правил игры» возможна при реализации международной и иной политики, осуществляемой между отдельными государствами. Однако добиться полной формализации достаточно богатого фрагмента научного знания невозможно. Формализация в любом ее проявлении - это способ фиксирования знания в виде информации и работы с ним как с информацией, но это не инструмент самого познания, не способ открытия, получения нового знания. Цифровизация же - это то, что осуществляется «задним числом» ${ }^{3}$.

Нужны системные интегрированные информационные аналитические ресурсы, в которых отобразится опыт прошлых поколений и передовая мысль ныне живущих. Важно соединение прошлого опыта и настоящих ощущений (рефлекции), которые предупреждают человека о наступлении непредсказуемых изменений в окружающей действительности, тем самым минимизируя риски, которые мы пока не можем объективно оценить и адекватно ответить на возникающие вызовы, чтобы через мощнейшее информационное интеллектуальное напряжение человеческого разума, но и с помощью «машины» с высоким уровнем «интеллекта», в т.ч. на уровне нейроданных, сформировать алгоритмы работы с рассеянной информацией, обработки собранных знаний и получения качественного контента. Такая по-настоящему человеческая цифровая экосистема сможет стать основанием для принятия выверенных стратегических решений, в т.ч. на политическом и управленческом уровне. А это, в

\footnotetext{
1 Медиалогия - разработчик автоматической системы мониторинга и анализа СМИ и соцмедиа в режиме реального времени. Доступ: http://www.mlg.ru/

2 Seldon.Basis собирает и анализирует сведения о компаниях и предпринимателях из официальных источников. Сервис для всесторонней оценки своих контрагентов - насколько добросовестно они выполняют взятые на себя обязательства: финансовые, контрактные, правовые. Доступ: https://basis. myseldon.com/ru

3 Солодухин Ю.Н. - научный руководитель Международного научно-учебного центра им. А.А. Зиновьева факультета глобальных процессов МГУ им. М.В. Ломоносова, специалист в области логики, методологии науки, политологии; кандидат философских наук, действительный государственный советник РФ I класса.
} 
свою очередь, позволит сформировать вероятный вариант будущего и провести преобразования в максимально позитивном русле.

Выиграют те, кто быстрее всех осознает изменения и при этом откажется от претензий на тотальную истину и тоталитарный подход к организации жизни. По всем показателям в мире такого еще не было: на тотальную реализацию всегда претендовала одна идея. Сейчас важно научиться строить системы, где разные подходы существуют одновременно, на разном материале - и либеральные, и директивные, и социалистические. Это невероятно сложный цивилизационный вызов 1 .

Еще раз подчеркнем, что Россия в этом смысле могла бы предложить мировому сообществу свои фундаментальные разработки в сфере выстраивания новой социогуманитарной картины мира, отказавшись от архаического технократизма и экономизма. Определенная же задержка России в вопросе цифровизации от развитых стран может дать неоспоримое преимущество стране в плане оценки уроков, чтобы не повторить ошибок первопроходцев, прежде всего в части сохранения и приумножения человеческого капитала.

При этом необходимо четко осознавать тот факт, что ни в теории, ни на практике никакая виртуальная реальность не заменит настоящую, хотя многие научные и публицистические издания, ученые и эксперты предлагают нам поверить на слово в то, что современный цифровой мир в его нынешней интерпретации позволит «построить мир изобилия» [Диамандис, Котлер 2018], за счет наращения новых технологических решений создать более совершенное общество. Так, например, Брет Кинг 2 безапелляционно заявляет, что «инновации будут использованы во благо: возникнут новые творческие профессии, сократятся часы работы, вырастут доходы» [Кинг 2018]. Но цифровая революция может не просто изменить, а разрушить до основания весь наш сегодняшний мир. И мы должны понимать, чем мы готовы платить за такие кардинальные изменения и какие из них мы приемлем, а какие - нет.

Таким образом, вопрос технологической революции сегодня - это, прежде всего, определение роли и места самого человека в социогуманитарной, политической и естественно-природной плоскости. Для осмысления такой стратегической парадигмы развития требуется разработка базисных философских и методологических основ современного общества с «цифрой в голове».

\section{Список литературы}

Бартлетт Дж. 2017. Подпольный интернет: темная сторона мировой паутины. М.: Эксмо. 352 с.

Диамандис П., Котлер С. 2018. Изобилие: будущее будет лучше, чем вы думаете. М.: АCТ. 608 c.

Зиновьев А. 2006. Фактор понимания. М.: Алгоритм. 528 с.

Кин Э. 2016. Ничего личного: как социальные сети, поисковые системы и спеислужбы используют наши персональные данные. М.: Альпина Паблишер. 224 с.

Кинг Б. 2018. Эпоха дополненной реальности. М.: Олимп-Бизнес. 528 с.

Куницын А.П. 2011. Право естественное. М.: ЛКИ. 162 с.

Лепский В.Е. 2012. Социогуманитарная эргономика стратегического проектирования российского развития. - Актуальные проблемы психологии труда, инженерной психологии и эргономики. Вып. 4. М.: Изд-во Института психологии PAH. C. 351-368.

\footnotetext{
1 Лейбин В. Царь-выборы. - Русский репортер. 2018. № 5(444). 12-26 марта. Доступ: http://expert. ru/russian_reporter/2018/05/tsar-vyiboryi/

2 Бретт Кинг - автор бестселлеров, эксперт-футуролог, известный журналист и телеведущий.
} 
Фромм Э. 1992. Марксова концепция человека. - Душа человека. М.: Республика. С. 375-414.

CHERNYSHOV Aleksei Gennad'evich, Dr.Sci. (Pol.Sci.), Professor of the Chair of State and Municipal Management, Financial University under the Government of the Russian Federation (49 Leningradsky Ave, Moscow, Russia, 125993; ag555@mail.ru)

\title{
STRATEGY AND PHILOSOPHY OF DIGITALIZATION
}

Abstract. Today, many problems of digitalization are associated exclusively with the use of various information and computer technologies, mathematical and other models. In fact, digitalization, first of, is a socio-political and socio-humanitarian problem. That is why we cannot do without understanding the methodological and strategic objectives of the current and future digitalization in relation to the development and finding the person himself in the digital world.

Keywords: person in digital world, socio-humanitarian development factor, technization of society, digital economy, philosophy of digitalization

ЖВИТИАШВИЛИ Анатолий Шалвович - кандидат исторических наук, ведущий научный сотрудник отдела социальной структуры Института социологии ФНИСЦ РАН (117218, Россия, г. Москва, ул. Кржижановского, 24/35, корп. 5; zhvitiashvili-a@mail.ru)

\section{ТРАНСФОРМАЦИЯ ПРАВЯЩЕГО КЛАССА В ЗАПАДНОМ ОБЩЕСТВЕ}

\begin{abstract}
Аннотация. В статье рассматриваются основные факторы трансформации правящего класса в западном обществе. В отличие от правящих классов прошлого, современный правящий класс представляет собой более широкую социальную общность: он включает в себя не только собственников средств производства, но и социальные слои, не владеющие средствами производства. Среди основных факторов эволюции правящего класса выделены такие процессы, как размывание грани между собственниками и не собственниками, развитие государства всеобщего благосостояния, переход к инновационному типу собственника, глобализация. Эти процессы существенно усложнили социальный состав правящего класса в современном западном обществе. Поэтому он не является чем-то монолитным и однородным. В нем, нередко в конфликтной форме, взаимодействуют разные группы интересов, отражающие противоречия современной эпохи. Особенность современному правящему классу придает дифференциация на национальный и транснациональный (глобальный) сегменты. Их взаимодействие во многом определяет дееспособность современного правящего класса.
\end{abstract}

Ключевые слова: современное западное общество, трансформация, правящий класс, основные факторы трансформации правящего класса, собственники и не собственники

Постановка проблемы. Деление общества на управляющих и управляемых существует с тех пор, как возникло разделение труда. Еще Платон отмечал, что потребность в разделении труда вытекает из несамодостаточной природы индивидов. Деление на классы управляющих и управляемых - устойчивый признак любого общества. В зависимости от эпохи это деление принимает разные формы. Свою специфику оно имеет и в условиях современного общества.

Проблемное поле статьи образует положение о том, что в современную эпоху правящий класс, под которым обычно подразумевают класс собствен- 